\title{
XXXV. Electromagnets.-IV. Cast iron, charcoal iron, and malleable cast iron
}

\section{R.H.M. Bosanquet}

To cite this article: R.H.M. Bosanquet (1885) XXXV. Electromagnets.-IV. Cast iron, charcoal iron, and malleable cast iron, Philosophical Magazine Series 5, 20:125, 318-323, DOI: $10.1080 / 14786448508627763$

To link to this article: http://dx.doi.org/10.1080/14786448508627763

册 Published online: 29 Apr 2009.

Submit your article to this journal $₫$

Џ Article views: 2

Q View related articles $₫$ 
light disappeared each time. It follows from this, as well as from former observations of Hittorf* and $W$. Siemens $\dagger$ on the luminosity of flames, that up to the temperature of melting iridium, gases possess no perceptible emissive power, if they are not concerned in chemical changes or in electric discharges. The cessation of luminosity at the white heat of the electrodes may perhaps be explained by the hot metallic vapours taking over the conduction, so that only a small fraction of the current goes through the hydrogen or nitrogen, which is not sufficient to bring it to luminosity. The conditions under which metallic vapours emit light may be quite different from those which hold good for ordinary gases. The investigations of Schuster $\ddagger$ have shown, at least, that mercury vapour in a vacuum tube, from which every trace of other gas has been expelled, presents essentially different and, in fact, simpler phenomena, so that the electric discharge takes place without glow-light, dark space, or stratifications. Whether Schuster's explanation is correct, that the reason is to be found in the simpler constitution of mercury vapour, or whether metallic vapours generally do not show this simpler mode of discharge, seems to be worthy of further investigation. Since I have myself always seen an unstratified coherent mass of light flling the space between the electrodes in an arc of 3 centim. in length, the second possibility appears to me the more probable.

Physical Institute,

University of Strassburg.

XXXV. Electromagnets. - IV. Cast Iron, Charcoal Iron, and Malleable Cast Iron. By R. H. M. BosarqUeT, St.John's College, Oxford.

To the Editors of the Philosophical Magazine and Journal. GenTLEMEN,

TTHE following measures of permeabilities have been made on a number of rings of cast iron, charcoal iron, and malleable cast iron. The magnetizing forces used varied in all cases from small forces to forces large enough to raise the metal to a condition but little removed from saturation. I do not include at present any comparisons with formulæ, as the facts are perhaps best kept separate in the first instance. These measures complete all the experiments on rings which I have contemplated so far.

It may be convenient to summarize shortly some chief points of the results of all the experiments on rings.

* Wied. Ann. vii. p. 587 (1879). † Ibid. xviii. p. 311 (1883).

$\ddagger$ Proc. Roy. Soc. xxxvii. p. 317 (1884). 
Mr. R. H. M. Bosanquet on Electromagnets.

Permeabilities or Susceptibilities.

\begin{tabular}{|c|c|c|c|c|}
\hline & $\begin{array}{c}\text { Small } \\
\text { inductions. }\end{array}$ & Maximum & $\begin{array}{l}\text { Permeability for } \\
\mathfrak{Z}=10,000 \text {. }\end{array}$ & $\underset{16}{\text { For }}=14,000^{*}$. \\
\hline Cast iron ... & $\left\{\begin{array}{l}50 \\
80\end{array}\right.$ & $\begin{array}{l}170 \\
250\end{array}$ & $\begin{array}{l}30 \\
80\end{array}$ & \\
\hline Malleable cast iron ... & $\left\{\begin{array}{l}160 \\
240\end{array}\right.$ & $\begin{array}{l}700 \\
800\end{array}$ & $\begin{array}{l}400 \\
500\end{array}$ & $\begin{array}{r}20 \\
100\end{array}$ \\
\hline Wrought iron. & $\left\{\begin{array}{l}200 \\
450\end{array}\right.$ & $\begin{array}{l}1800 \\
2500\end{array}$ & $\begin{array}{l}1200 \\
2000\end{array}$ & $\begin{array}{r}500 \\
1000\end{array}$ \\
\hline Chareoal iron & $\left\{\begin{array}{l}450 \\
470\end{array}\right.$ & $\left.\begin{array}{l}2900 \\
3000\end{array}\right\}$ & 2000 & $\begin{array}{l}600 \\
860\end{array}$ \\
\hline Cast tool steel (hard)... & $\left\{\begin{array}{l}40 \\
50\end{array}\right.$ & $\begin{array}{l}145 \\
155\end{array}$ & $\begin{array}{l}100 \\
130\end{array}$ & $\begin{array}{l}70 \\
86\end{array}$ \\
\hline$" \quad, \quad$ (soft) $\ldots$ & $\left\{\begin{array}{r}90 \\
120\end{array}\right.$ & $\begin{array}{l}420 \\
460\end{array}$ & $\left.\begin{array}{l}350 \\
450\end{array}\right\}$ & 200 \\
\hline
\end{tabular}

Saturation-points.

$\mathbf{B B}=$

Oast iron ............................... $9,000-14,000$.

Malleable cast iron ......................... $14,000-16,000$

Wrought iron ?

Charcoal iron

$17,000-19,000$.

Cast tool ateel, both hard and soft ..... 20,000.

The malleable cast-iron rings were supplied to me by Messrs. Crowley, of Sheffield. The material cuts exactly like charcoal iron; and it seemed probable that its magnetic qualities might be similar to those of charcoal iron. In this case the possibility of casting the material would have been of the highest importance with reference to dynamo machines.

The results for ordinary cast iron show that it is wholly unfit for use in dynamo machines; the low saturation-point being particularly objectionable. The malleable cast iron would undoubtedly be a great improvement on ordinary cast iron; but still inferior to wrought iron.

It may be noted that the variations of temper in the different rings of malleable cast iron did not appear to correspond to any recognizable differences, either mechanical or magnetic.

About the time these experiments were drawing to a close I became aware, by a notice in 'Nature,' that Dr. Hopkinson had communicated to the Royal Society a series of investigations apparently similar to my own. I have not yet been able to learn any thing about the contents of the paper in question; but considering the diversity of the properties of different specimens, as well as of the methods in use, I still hope that my results may not be without usefulness.

* As before, $\mathfrak{B}$ stands for the magnetic induction, or number of lines of force across unit area; $\mu$ for permeability or susceptibility. 
Mr. R. H. M. Bosanquet on Electromagnets.

Tables of Results.
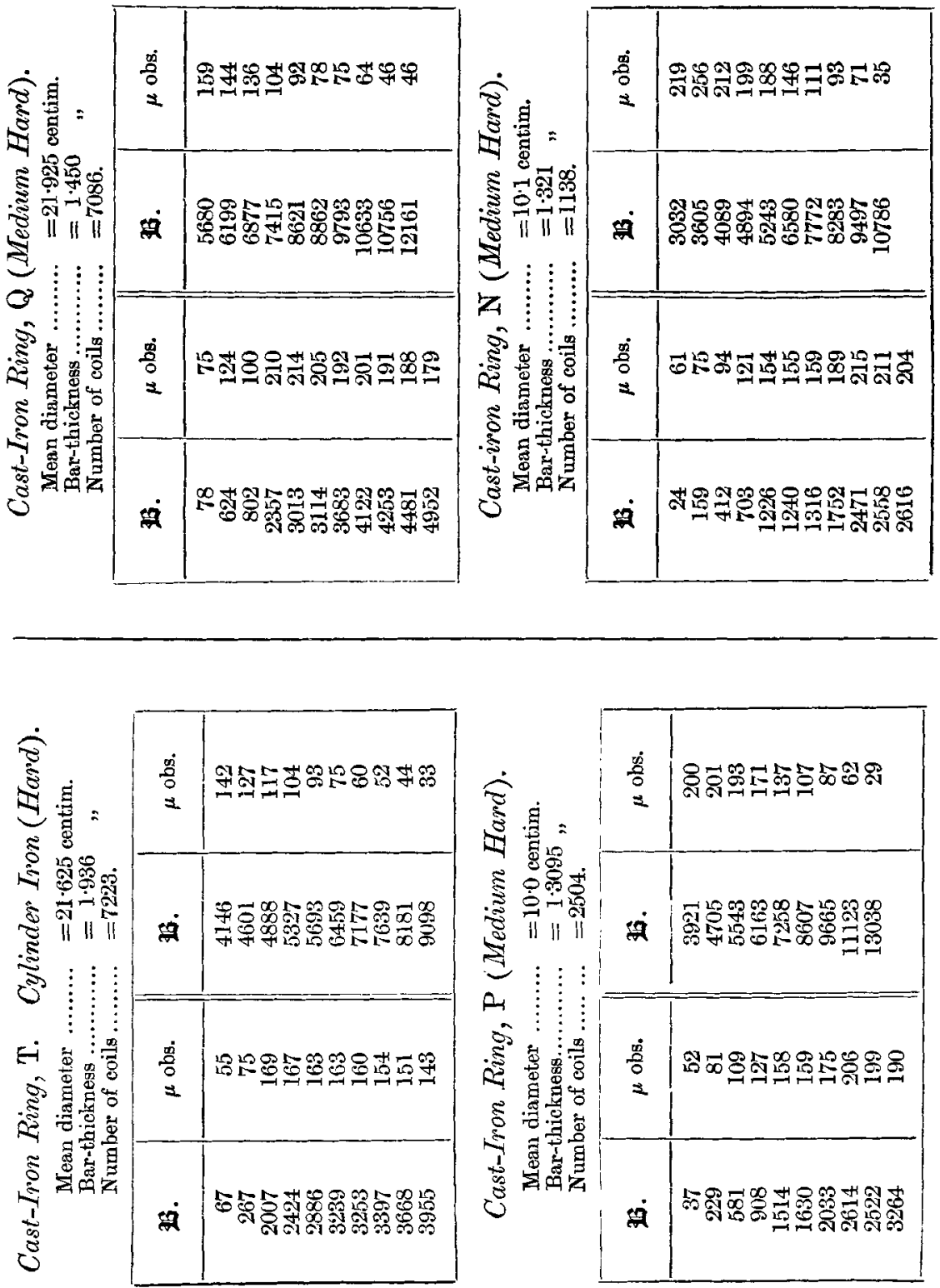
Mr. R. H. M. Bosanquet on Electromagnets.

\begin{tabular}{|c|c|c|c|c|c|}
\hline$\stackrel{\dot{\vec{\sigma}}}{\stackrel{0}{0} .}$ & 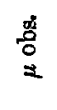 & 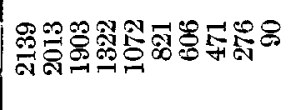 & \multirow{4}{*}{ 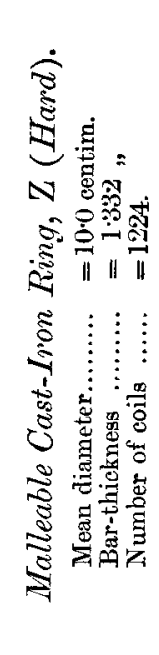 } & 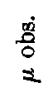 & 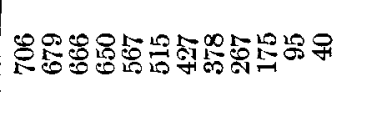 \\
\hline 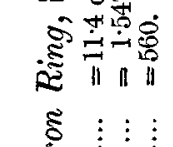 & बी & 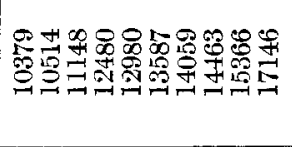 & & வ் & 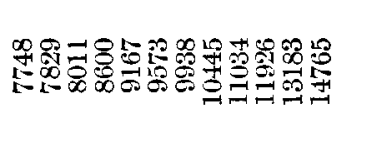 \\
\hline 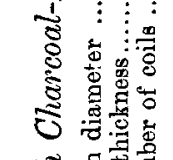 & $\begin{array}{l}\stackrel{t}{0} \\
z \\
z\end{array}$ & 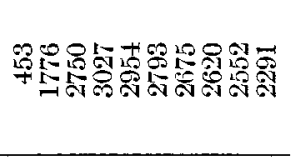 & & $\begin{array}{l}\frac{d}{0} \\
z\end{array}$ & 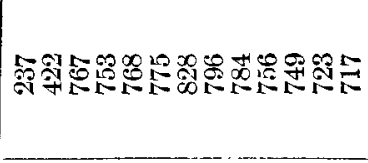 \\
\hline 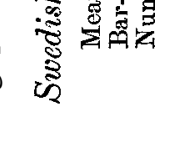 & $\mathbb{a}$ & 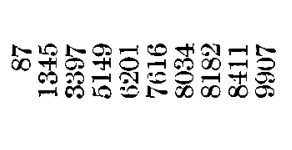 & & $\dot{9}$ & 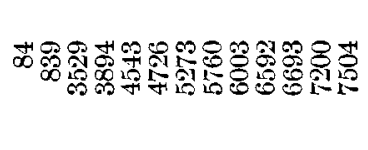 \\
\hline
\end{tabular}
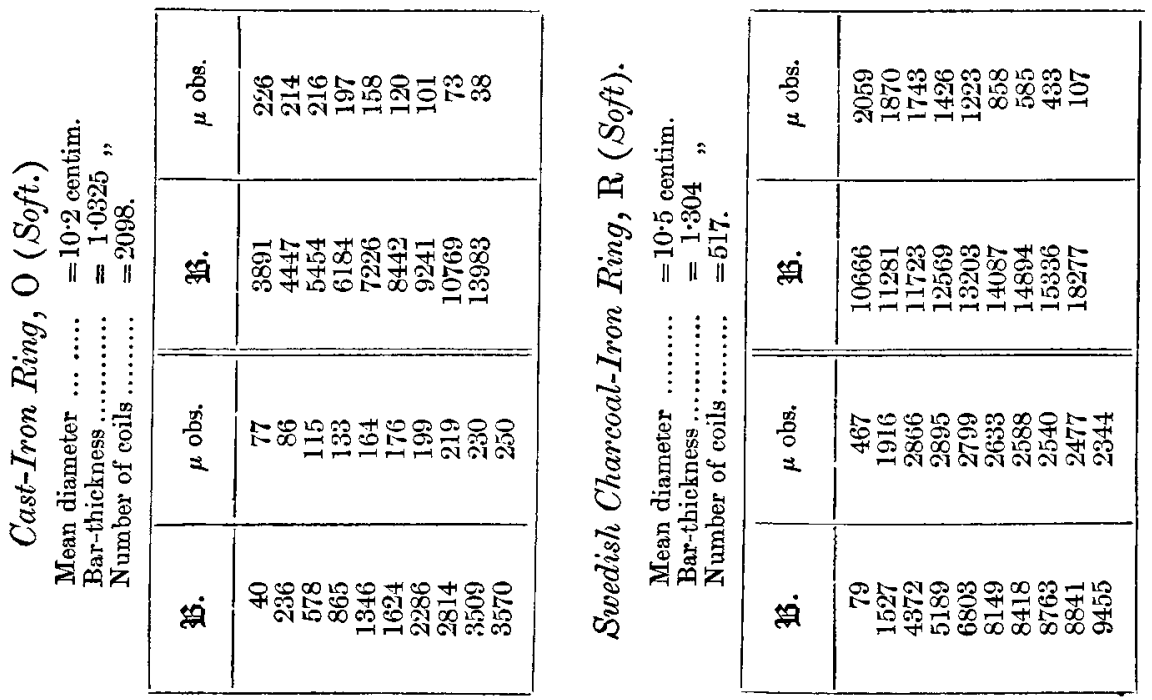

Phil. Mag. S. 5. Vol. 20. No.125. Oct.1885. 2 A 


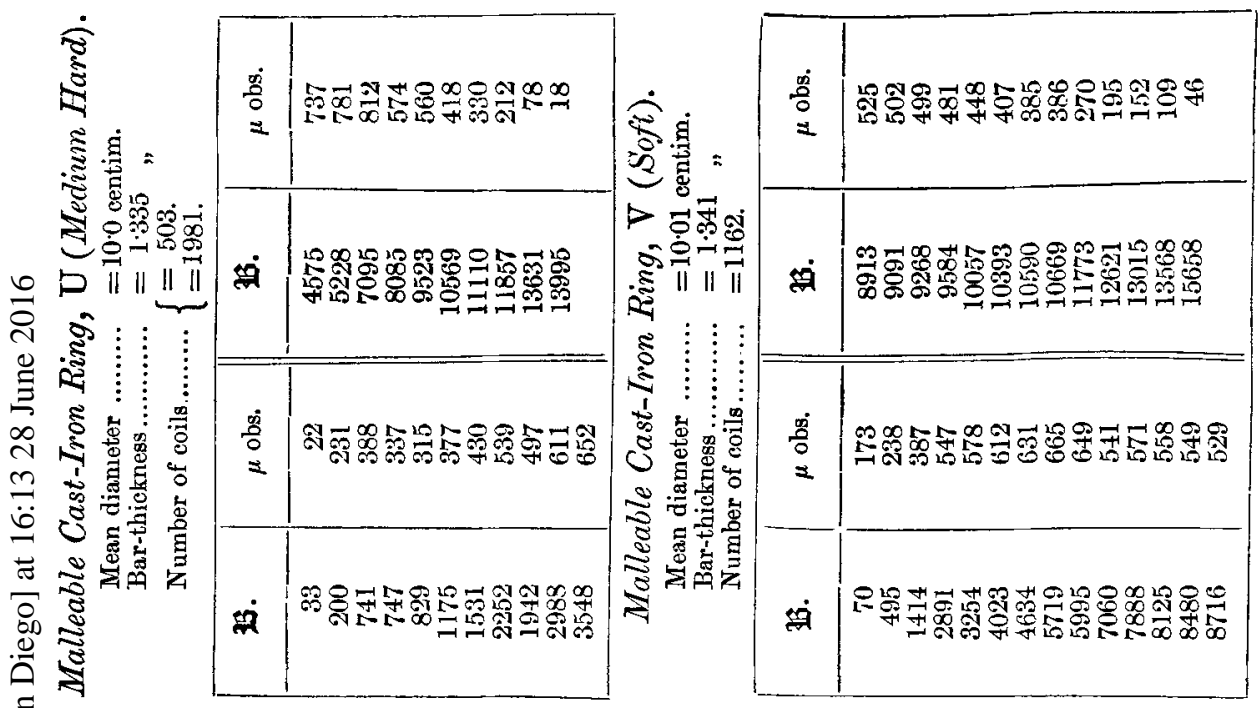

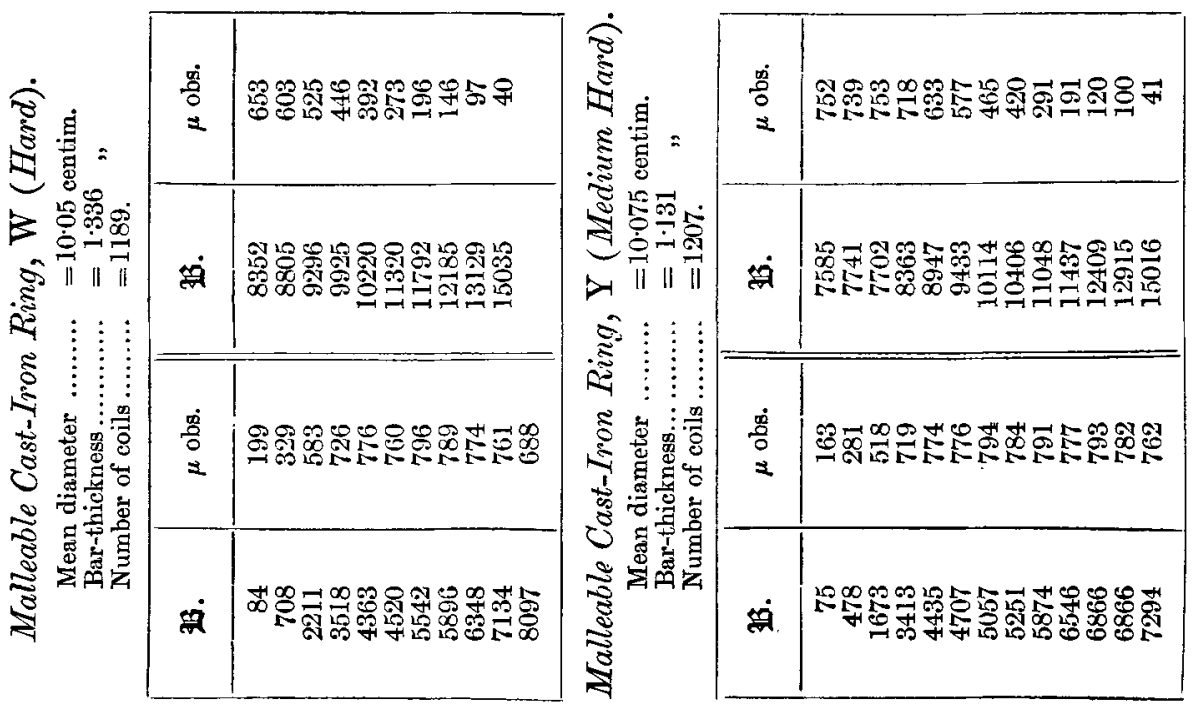


Malleable Cast-Iron Ring, X (Soft).

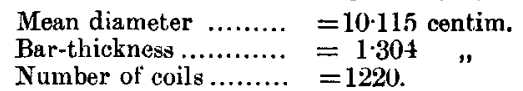

\begin{tabular}{|c|c|c|c|}
\hline 16. & $\mu$ obs. & BB. & $\mu$ obs. \\
\hline 62 & 178 & 7144 & 735 \\
\hline 76 & 146 & 7628 & 724 \\
1293 & 491 & 7669 & 755 \\
3784 & 712 & 8759 & 715 \\
3976 & 701 & 9142 & 626 \\
4395 & 717 & 9526 & 618 \\
4622 & 767 & 10373 & 495 \\
5045 & 746 & 11080 & 417 \\
5247 & 746 & 11907 & 276 \\
54.9 & 753 & 12412 & 217 \\
5853 & 754 & 12876 & 173 \\
6196 & 759 & 13562 & 115 \\
6781 & 762 & 15762 & 47 \\
\hline
\end{tabular}

XXXVI. On the Influence of Heat on the Rate of Chemical Change. By JoHn J. Hood, D.Sc. (Lond.)*.

THE accelerating action of heat on the rate at which a 1 chemical change progresses has been made the subject of investigation by several chemists. The amount of work that has been done towards the elucidation of this side of the great problem of chemical action, expressing the rate as a function of the temperature, is as yet too insignificant to allow of any deductions being drawn relative to the probable mechanical processes that take place in a medium containing a chemical system undergoing change. Considered in the light of molecular interdiffusion, it would seem probable that the relation between the rate of change of different chemical systems comprising two or more active bodies (active in a chemical sense) ind the temperature should be of the same type; and the experiments that have been made on this subject all seem to show this in common, that the rate of the change increases very rapidly for small increments of temperature.

Warder $t$, in his experiments on the speed of saponification of ethylic acetate, was led to infer that the increase of speed in this reaction is approximately as the second power of the temperature.

Mills and Mackey $\neq$, studying the evolution of hydrogen from zinc and hydric sulphate at different temperatures, a case of a chemical system of a non-homogeneous character,

* Communicated by the Author.

+ American Chemical Journal, vol. iii.

$\ddagger$ Phil. Mag. [5] xvi. 